\title{
VIEWPOINT
}

\section{How Community and Unity Can Help Americans Survive}

\author{
Robert H. Brook, M.D, S.cd ${ }^{7,2}$, C. Jason Wang, M.D., PhD ${ }^{3,4}$, and Neil S. Wenger, M.D, \\ M.P.H. ${ }^{5}$ \\ 'Health Care Services, RAND Corporation, Santa Monica, CA, USA; ${ }^{2}$ David Geffen School of Medicine at UCLA, Los Angeles, CA, USA; \\ ${ }^{3}$ Departments of Pediatrics and Medicine, Stanford University, Stanford, CA, USA; ${ }^{4}$ Center for Policy Outcomes and Prevention, Stanford University, \\ Stanford, CA, USA; ${ }^{5}$ Division of General Internal Medicine and Health Services Research, David Geffen School of Medicine at UCLA, Los Angeles, \\ CA, USA.
}

$\mathrm{J}$ Gen Intern Med 35(6): 1879-80

DOI: $10.1007 / \mathrm{s} 11606-020-05829-8$

(c) Society of General Internal Medicine 2020

B y now, most of the world knows about COVID-19 and has seen haunting images of its impact from China and Italy. The virus is in the USA and Americans are justifiably frightened. Health professionals fear the prospect of being overwhelmed with sick people and forced to make life and death decisions due to inadequate resources. People hope that social distancing, isolation of virus-positive people, perhaps even the summer heat, or the emergence of a new drug will help to contain the virus and prevent an even more deadly health calamity. But when faced with an escalating pandemic, rapid preparation is required, converting from an ethic of individualism to a communitarian ethic in which everyone benefits. What follows are some specific tasks that could be done now to arm us for the fight, including steps by health care providers, government, business, and individuals.

At the community level, the US health care system comprises a series of distinct health systems - in Los Angeles, for example, these include Kaiser, UCLA, Cedar Sinai, LA County, USC, and the VA. Ordinarily, these systems compete for dollars and patients. But if forecasts are true, the epidemic will severely stress all of these systems perhaps beyond their capacity. Working together could maximize the efficient use of each system's capacity. A command center could be formed in each community that tracks, on a real-time basis, the stress in the entire system in terms of parameters such as the number of medical personnel available to work in the hospitals/clinics/ nursing homes or remotely through telemedicine; available hospital beds; available ICU beds; and availability of scarce resources such as test kits, swabs, masks, medicines, and ventilators. This information could be used to triage patients, personnel, and equipment to facilities. The command center staff could include people who know data systems and

Received March 25, 2020

Revised March 25, 2020

Accepted March 26, 2020

Published online April 13, 2020 management, analytics, and AI. The center would not need to have perfected the metrics/systems to get started; it could learn and perfect its algorithms with time, experience, and data. To increase trust, the press could be part of the center so that fact-based information could be communicated directly to the public rapidly and reliably.

To determine which patients should receive aggressive hospital or ICU care, it would be important to know the risk of dying/recovering with or without such care. If the goal is to protect the health of the public, tough decisions will have to be made on the use of precious resources on individuals who will survive or die with or without them. Transfers from home or nursing home of patients who will not benefit from inpatient care are wasteful and often disrespectful. In wartime, overwhelmed medics make these types of decisions in real time based on their personal judgment. This could be improved by using modern analytic capabilities, including prognostic models that could be improved with experience. The USA has experts in the field of health services research and data scientists in both the private and public sectors who, with data, could answer this question quickly. Because practice patterns are likely to be different in China and Italy, with less aggressive treatment for older, sicker patients, the dire associations of age and comorbidities may not apply in the USA. As with the command center, early models could be improved with experience.

The current crisis emphasizes the need to match treatment with patient goals and prognosis. With working prognostic models, patients could be guided to the treatments that will most likely achieve those goals. That means talking with patients in focused ways to elicit goals in context. If, as the international data suggest, this disease affects the elderly much more severely than the young, then discussions could focus on how best to treat patients who may not wish to be hospitalized, intubated for days or weeks. At the same time, scarce resources could best be deployed where they can realistically achieve patients' goals. Now is the time to redouble efforts to understand patients' goals and values and make sure they are documented in electronic medical records and honored. Patients should be assured that they will receive the comfort care they need if that is their desire. And this should not occur in a crowded hospital. 
This would ask a lot of America's health care professionals. They are on the front line and they should be provided with necessary protections. Currently, there are not enough gowns, hazmat suits, masks, and gloves. Public and private efforts to produce these products could proceed at a war-time pace because this is a war. Physicians whose practices are on hold could offer their masks, gowns, and other equipment to those fighting the virus. Medical workers also could be offered mental health support, day care, a place to live that is separate from family members whom they do not want to infect, and transportation to and from the hospital after they have worked for 36 hours straight so that they do not fall asleep at the wheel.

Telemedicine that is already happening in many places could be expanded to providers who are quarantining at home, providers in a vulnerable category due to age or a medical condition, and retired physicians and nurses. These providers could form a telemedicine team so that younger, healthier, non-exposed health care professionals can staff the front lines. This could also happen quickly and draw on both the public and private sectors. Any regulations limiting telemedicine across state lines could be immediately dropped.

Health personnel throughout the country could help each other. Immediately making it possible for physicians and nurses to practice in any state or health system or hospital if they are licensed and credentialed in one of them could help. If providers need to move around the country, the airlines, which currently have excess capacity, could help.

But health care providers cannot do it alone; companies and individuals also have roles to play. If America is truly on a war footing, everyone can bring something to the effort, guided by the country's historic moral compass.

Many young people are not in school because schools are closed; others can work only part-time or have been furloughed due to the virus' impact. They could offer their help. Providers need caregivers for their children and help with buying groceries and other tasks. Similarly, workers whose children are not in school need childcare. Individuals with analytic skills could volunteer for the command center. Disadvantaged persons will need special attention. Each community could establish a system to help its residents volunteer their time and skills. The community would likely respond, particularly youth.
Corporate America could pitch in as well. Manufacturers could prioritize the most needed products. Labs could work quickly to develop accurate tests and affordable medications and vaccines. Medical advances could be shared with the world. Companies could consider ways to save jobs by sharing the pain across all employees. For example, executives could take a pay cut to protect jobs at lower levels and employees could work $80 \%$ time to avoid furloughs.

Americans have already witnessed examples of extraordinary leadership. However, for the types of actions just described, many more leaders among health care providers, government, businesses, educators, and community could step in to seize the initiative and act decisively. If all Americans follow their best moral compass, the COVID-19 war may best be won in a way that respects the nation's history and values and keeps as many people as possible safe and well and treats everyone with dignity and respect. This portends to be a catastrophe that will affect a huge proportion of the population; Americans could act together to minimize the damage and show that a nation united can prevail. The UK survived World War II with unity, courage, and innovation - think Bletchley Park. The USA can survive COVID-19 the same way.

Corresponding Author: Robert H. Brook, M.D, S.cd; Health Care Services RAND Corporation, Santa Monica, CA, USA (e-mail: robert_ brook@rand.org).

\section{Compliance with Ethical Standards:}

Conflict of Interest: The authors declare that they do not have a conflict of interest.

Publisher's Note: Springer Nature remains neutral with regard to jurisdictional claims in published maps and institutional affiliations. 